\title{
A novel clip closure method using precutting and a reopenable clip after colorectal endoscopic submucosal dissection
}
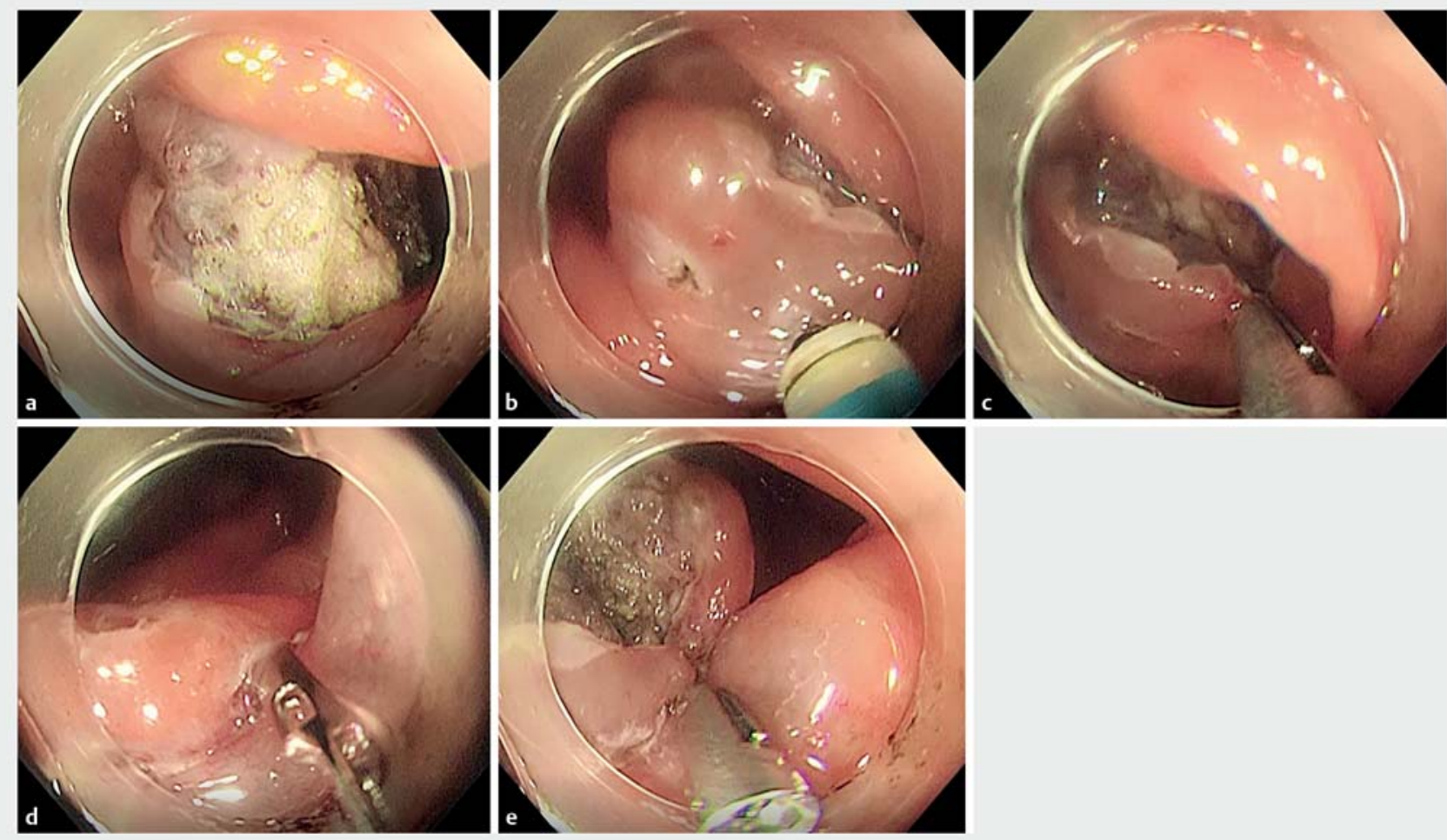

- Fig. 1 Representative case in which clip closure after colorectal endoscopic submucosal resection (ESD) was carried out using precutting and a reopenable clip. a A 70-mm laterally spreading tumor in the ascending colon was removed by ESD, resulting in a large mucosal defect. b Additional incisions were made with a DualKnife J on the oral and anal sides of the mucosal defect. $\mathbf{c}$ A reopenable clip was used to grasp the anal incision and margin of the mucosal defect. $\mathbf{d}$ While holding its grasp, the clip was moved to the opposite side of the mucosal defect and reopened to grasp the incision on the oral side. e Closure was successful. After that, the same procedure was repeated as needed to complete the closure.

Clip closure of mucosal defects after endoscopic resection has been shown to reduce delayed adverse events [1,2]; however, closing large defects using a conventional clip can be difficult [1] Thus, alternative clip closure techniques have been developed, but they still need improvement in terms of simplicity and solderability $[3,4]$. We therefore modified an existing precutting technique [4] using a reopenable clip to close large mucosal defects.

After resection of the lesion, multiple small incisions were performed circumferentially just outside the defect using a DualKnife J (Olympus, Tokyo). A reopen- able clip (SureClip, Microtech, Nanjing) was opened, and one side of the claw was inserted into the incision on the anal side, while the other side of the claw was placed just inside the margin of the defect, and the claws were closed while catching the normal mucosa. Bringing the caught mucosa closer to the oral side of the defect, the clip was reopened to insert the opposite side of the claw into the oral-side incision. Finally, the claws were completely closed, and the normal mucosae of both sides were drawn together. The combination of mucosal incision and mucosal catching using a reopenable clip was easily achieved without clip slipping.
After repeating the same procedures to minimize the defects, regular clips were added to close the defect completely. This method was applied in three patients with defect sizes between 33 and $71 \mathrm{~mm}$ located in the ascending colon, transverse colon, and rectum. The median (range) procedure time was 20 (10-26) minutes. Complete closure was easily achieved in all cases, and there were no adverse events during the perioperative period. A representative case is shown in $\checkmark$ Fig. 1 and $>$ Video 1.

In conclusion, using a reopenable clip with multiple precut small circumferential mucosal incisions is an excellent 


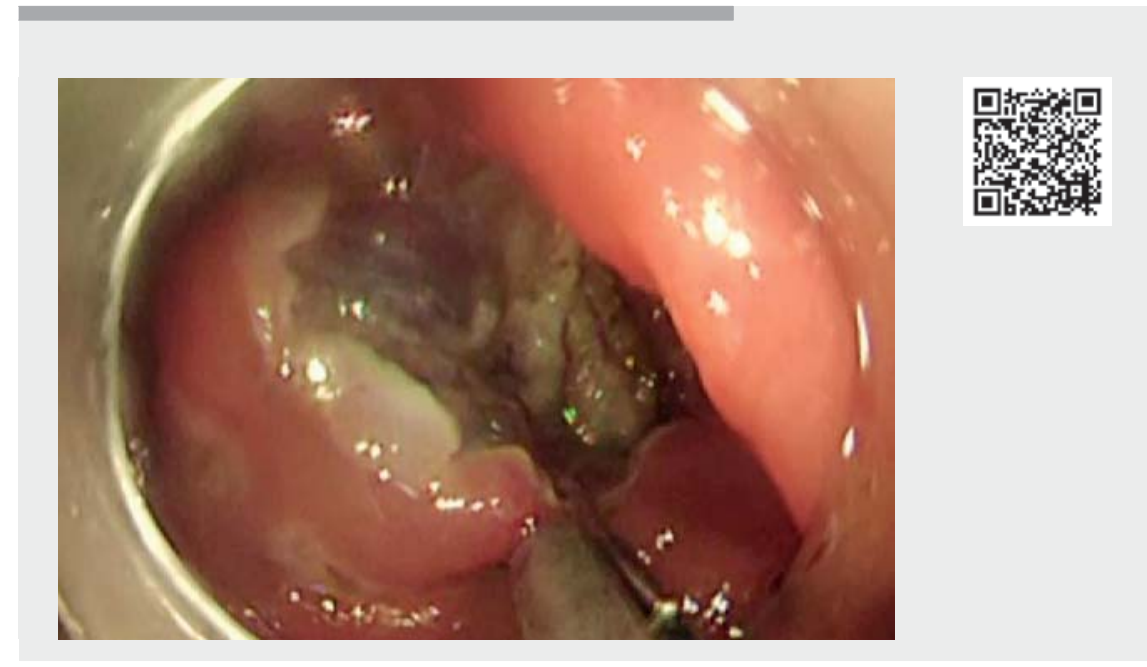

$\checkmark$ Video 1 A novel clip closure method using mucosal precutting and reopenable clips to close large mucosal defects after endoscopic submucosal dissection for colonic lesions. Complete closure was easily achieved using this novel method.

method to facilitate the complete closure of large mucosal defects.

\section{Endoscopy_UCTN_Code_TTT_1AQ_2AJ}

\section{Acknowledgment}

We express our sincere gratitude to the medical staff in our endoscopy unit for their cooperation, and to Editage for editing a draft of this manuscript.

\section{Competing interests}

The authors declare that they have no conflict of interest.

\section{The authors}

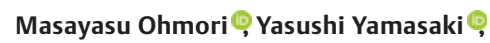
Shumpei Yamamoto, Hideaki Kinugasa, Keita Harada, Sakiko Hiraoka, Hiroyuki Okada Department of Gastroenterology, Okayama University Hospital, Okayama, Japan

\section{Corresponding author}

\section{Yasushi Yamasaki, MD}

Department of Gastroenterology, Okayama University Hospital, 2-5-1 Shikata-cho, Kita-ku, Okayama 700-8558, Japan yasshifive@yahoo.co.jp

\section{References}

[1] Chen B, Du L, Luo L et al. Prophylactic clips to reduce delayed polypectomy bleeding after resection of large colorectal polyps: a systematic review and meta-analysis of randomized trials. Gastrointest Endosc 2021; 93: 807-815

[2] Zhang QS, Han B, Xu JH et al. Clip closure of defect after endoscopic resection in patients with larger colorectal tumors decreased the adverse events. Gastrointest Endosc 2015; 82: 904-909

[3] Yamasaki Y, Takeuchi Y, Iwatsubo T et al. Line-assisted complete closure for a large mucosal defect after colorectal endoscopic submucosal dissection decreased post-electrocoagulation syndrome. Dig Endosc 2018; 30: 633-641
[4] Otake Y, Saito Y, Sakamoto T et al. New closure technique for large mucosal defects after endoscopic submucosal dissection of colorectal tumors (with video). Gastrointest Endosc 2012; 75: 663-667

Bibliography

Endoscopy 2022; 54: E401-E402

DOI 10.1055/a-1559-1586

ISSN 0013-726X

published online 27.8.2021

(c) 2021. Thieme. All rights reserved.

Georg Thieme Verlag KG, Rüdigerstraße 14, 70469 Stuttgart, Germany

\section{ENDOSCOPY E-VIDEOS}

https://eref.thieme.de/e-videos

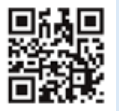

Endoscopy E-Videos is an open access online section, reporting on interesting cases and new techniques in gastroenterological endoscopy. All papers include a high quality video and all contributions are freely accessible online. Processing charges apply (currently EUR 375), discounts and wavers acc. to HINARI are available.

This section has its own submission website at https://mc.manuscriptcentral.com/e-videos 